\title{
HUBUNGAN ANTARA PEMBERDAYAAN DENGAN KEPUASAN KERJA KARYAWAN DI PT. BATAVIA BINTANG BERLIAN PULOGADUNG
}

\author{
LEONI SANTIKA \\ Alumni Fakultas Ekonomi Universitas Negeri Jakarta \\ HENRY ERYANTO \\ Dosen Fakultas Ekonomi Universitas Negeri Jakarta \\ MAISAROH \\ Dosen Fakultas Ekonomi Universitas Negeri Jakarta
}

\begin{abstract}
This study aims to determine whether there is a relationship between empowerment and job satisfaction in employees at PT. Batavia Bintang Berlian in Jakarta Timur. The research was carried out for 3 months from April 2014 to June 2014. The method used was a survey method with the correlational approach. The study population was all employees in the PT. Batavia Bintang Berlian Showroom Mitsubishi, amounting to 120 employees, and affordable population of this study is that employees are placed in marketing totaled 60 people. The samples are 51 respondents using proportional random sampling. To collect data from both variables, the instruments used for the variable $X$ (Empowerment) and $Y$ variables (Job satisfaction) is shaped questionnaire. Before use, test the construct validity (Construct Validity) through the validation process is the calculation of the correlation coefficient score points with the total score and reliability tests with Cronbach alpha formula. Result reliability of the instrument variable $X$ (Empowerment) of 0,899 and instrument variable $Y$ (Job satisfaction) of 0.936. The test requirements analysis was to find the regression equation obtained was $Y=37.32+0.717 X$. Liliefors normality test results produced $L_{\text {hitung }}=0.065$ and $L_{\text {tabel }}=0.124$ at significance level $(a)=0.05$ for the number of samples $(n)=51$. Because $L_{\text {hitung }}=(0.065)<L_{\text {tabel }}=(0.124)$ then the variables $X$ and $Y$ are normally distributed. Testing the hypothesis by testing the significance of regression produces $F_{\text {hitung }}=37.40>f_{\text {tabel }}=$ (4.04), which means that the regressin equation is significant. Linearity regression test produces $F_{\text {hitung }}=0.72$ and $F_{\text {tabel }}=2.05$ so $F_{\text {hitung }}<F_{\text {tabel }}$ table it can be concluded that the model is a linear regression equation. Product moment correlation coefficient test result $r_{\text {hitung }}=0.658$. further test the significance of the correlation coefficient using $t$-test, yielding $t_{\text {hitung }}=(6.12)>t_{\text {tabel }}=(1,68)$. Results of these studies concluded that there is a positive relationship between empowerment and job satisfaction in employees. With a coefficient of determination or determining test results obtained $43.29 \%$ job satisfaction variable $(Y)$ is determined by the empowerment $(X)$.
\end{abstract}

\section{PENDAHULUAN}

Era pasar bebas mengakibatkan tingginya persaingan disektor pelayanan jasa, termasuk tingginya peminatan akan kebutuhan alat transportasi bagi masyarakat. Persaingan dunia usaha yang semakin global mempengaruhi berbagai aspek pada suatu perusahaan, dimulai dari perubahan cepat kemajuan teknologi dan industrialisasi yang semakin berkembang dari waktu ke waktu menuntut perusahaan memiliki sumber daya manusia yang potensial yang mampu bersaing secara kompetitif.

Pembangunan sumber daya manusia atau karyawan merupakan salah satu prioritas utama 
pendukung setiap kegiatan terutama bidang perkantoran yang dilaksanakan oleh pemerintah maupun swasta. Untuk itu karyawan adalah kekayaan utama suatu perusahaan, karena tanpa keikutsertaan mereka, aktivitas perusahaan tidak akan terjadi. Karyawan berperan aktif dalam menetapkan rencana, sistem, proses, dan tujuan yang ingin dicapai.

Karyawan merupakan bagian terpenting yang dapat menghasilkan input pemasukan bagi perusahaan, terutama karyawan bagian marketing di sebuah perusahaan. Dimana bagian marketing merupakan yang paling sering berhubungan dengan konsumen sebagai penghubung perusahaan untuk mendapatkan penghasilan. Dan bagaimana karyawan mempresentasikan kepada konsumen dan meyakinkan mereka untuk membeli produk, agar apa yang diinginkan oleh perusahaan dapat tercapai.

Setiap karyawan bagian marketing tentu memiliki cara tersendiri bagaimana mereka melakukan pekerjaan yang dijalankannya saat ini, agar pekerjaan mereka dapat berjalan dengan baik, tentu mereka harus merasakan kepuasan dalam bekerja. Sebagai media penghubung antara pimpinan dan konsumen, karyawan harus paham akan tugas yang dijalankannya, agar tugas yang diemban oleh karyawan dapat berjalan dengan baik, dengan demikian diharapkan karyawan mendapatkan kepuasan dalam bekerja.

Kepuasan kerja pada karyawan mempengaruhi tingkat kepuasan pelanggan. Selain itu, kepuasan kerja juga akan membantu adanya perkembangan kualitas pelayanan bagi pelanggan. Oleh karena itu kepuasan kerja karyawan menjadi penting bagi keberlangsungan perusahaan. Hal ini menjadi perhatian yang serius bagi pihak manajemen perusahaan, karena berkaitan erat dengan tenaga dan keberlangsungan perusahaan yang bersangkutan.

Kepuasan yang diterima karyawan, nantinya akan dapat berwujud pelaksanaan kerja yang baik, penyelesaian tugas tepat waktu, ekspresi wajah ceria saat bekerja, dan kesetiaan kepada perusahaan. Namun sebaliknya, ketidakpuasan karyawan tentu akan mengakibatkan kerugian bagi perusahan akibat banyaknya karyawan yang melalaikan 
pekerjaan, tertundanya berbagai tenggat waktu tugas yang diberikan, menunjukkan ekspresi muka murung dan tingginya keinginan pada karyawan untuk pindah ke perusahaan lainnya.

Banyak faktor yang mempengaruhi kepuasan kerja karyawan antara lain stress kerja, gaya kepemimpinan, balas jasa, penempatan karyawan dan pemberdayaan. Oleh karena itu, setiap perusahaan harus dapat memberikan perhatian yang cukup terhadap faktor-faktor tersebut.

Beban pekerjaan yang berlebihan seringkali menimbulkan stress pada karyawan. Karyawan dituntut untuk menyelesaikan pekerjaan dibawah tekanan dan harus mencapai target yang telah ditentukan oleh perusahaan.

Tuntutan yang berlebihan dari manajer, jadwal kerja yang monoton, kurangnya dukungan supervisi, sering dibatalkannya perjanjian secara sepihak oleh klien secara tibatiba, serta sulitnya mengantisipasi maksud manajer juga merupakan faktor-faktor spesifik dari kondisi kerja yang seringkali menimbulkan stres pada karyawan. Stres tersebut membuat karyawan tidak nyaman dalam melaksanakan tugas-tugasnya, yang pada akhirnya berdampak pada menurunnya kepuasan kerja karyawan.

Gaya kepemimpinan turut mempengaruhi kepuasan kerja karyawan. Gaya kepemimpinan yang tepat, selain dapat membina hubungan yang baik antar karyawan dan bagian manajemen satu dengan yang lainnya, juga dapat membantu penyelesaian tugas-tugas karyawan. Gaya kepemimpinan yang seperti ini merupakan gaya kepemimpinan yang demokratis dimana pimpinan memberikan kebebasan kepada karyawan mengembangkan kreativitas dan inovasinya dalam menyelesaikan tugas-tugasnya sepanjang masih dalam standar operasional dan prosedur (SOP).

Bila pemimpin menerapkan gaya kepemimpinan yang tepat, seperti bersikap hangat, tidak semena-mena, berlaku adil, menghargai pekerjaan karyawan dan menjalin hubungan yang baik dengan karyawan, maka karyawan akan terpacu untuk bekerja dan memberikan yang terbaik bagi perusahaan sehingga dapat menciptakan kepuasan kerja. Namun pada kenyataannya, masih terdapat pemimpin yang menerapkan gaya kepemimpinan yang otoriter, menganggap 
rendah bawahan, tidak mau mendengar masukan dari karyawan, serta kurang memberikan dukungan dan bimbingan kepada karyawan sehingga akan berdampak pada menurunnya kepuasan kerja.

Balas jasa yang diterima oleh karyawan juga mempengaruhi kepuasan kerja. Terkadang karyawan merasa tidak adil dalam menerima balas jasa yang diberikan oleh perusahaan. Pemberian balas jasa berupa upah, gaji, hadiah, atau bonus sebagai imbalan atas hasil kerja karyawan yang tidak sesuai dapat menimbulkan ketidakpuasan kerja.

Apabila perusahaan memberikan balas jasa yang adil kepada karyawan yakni balas jasa atas hasil yang telah karyawan lakukan untuk perusahaan sesuai dengan beban kerja dengan standar balas jasa yang berlaku, tentu karyawan akan merasa senang dan menimbulkan kepuasan kerja. Akan tetapi, terkadang perusahaan memberikan balas jasa yang tidak sebanding dengan hasil yang telah karyawan lakukan untuk perusahaan, hal ini menimbulkan ketidakpuasan dalam diri karyawan.
Faktor yang tidak kalah penting yang mempengaruhi kepuasan kerja adalah penempatan kerja karyawan. The right man on the right place merupakan prinsip dalam penempatan kerja, diartikan orang yang tepat pada jabatan yang tepat. Apabila karyawan ditempatkan sesuai dengan keterampilan, keahlian dan pengetahuannya, maka penyelesaian pekerjaan akan berjalan dengan lancar dan selesai tepat waktu serta karyawan akan puas dengan hasil kerjanya. Namun pada kenyataannya, karyawan seringkali ditempatkan di bagian yang tidak sesuai dengan keterampilan, keahlian dan pengetahuannya, sehingga hasil kerja karyawan rendah dan hal tersebut menimbulkan ketidakpuasan karyawan dalam bekerja.

Pemberdayaan merupakan salah satu faktor yang mempengaruhi kepuasan kerja karyawan. Dengan adanya pemberdayaan, karyawan diberikan kebebasan dalam mengambil keputusan, ini memicu karyawan untuk memiliki tanggung jawab secara penuh terhadap pekerjannya, melatih karyawan dalam mengambil sebuah keputusan yang tepat, diberikan kepercayaan penuh dalam 
mengerjakan pekerjaannnya. Hal tersebut mobil dengan merek Mitsubishi saja, tetapi memacu karyawan untuk dapat mengerjakan juga melayani pembelian suku cadang, dan pekerjannya secara optimal sehingga dapat melakukan servis berkala bagi konsumen.

meningkatkan kepuasan kerja karyawan.

Masalah pemberdayaan karyawan yang

Karyawan yang diberdayakan merasa rendah juga terjadi pada karyawan di PT. dapat penghargaan dalam dirinya. Karena Batavia Bintang Berlian Pulogadung, terlihat karyawan yang diberdayakan dapat memiliki dari tanggung jawab yang diemban karyawan inovasi dalam melakukan pekerjaan yang kurang diiringi dengan pendelegasian dan digelutinya, sehingga apa yang ingin dicapai pelimpahan wewenang oleh pimpinan, sebagai oleh pimpinan akan dapat terwujud. Selain contoh terdapat karyawan yang lambat dalam dapat membuat karyawan menjadi inovatif, mengambil keputusan karena selalu menunggu karyawan juga dapat memiliki inisiatif untuk instruksi dari atasan yang mengakibatkan mengambil keputusan apa yang harus diambil pelanggan kecewa akibat lamanya proses ketika sedang menghadapi konsumen.

Namun cukup memprihatinkan perilaku banyak perusahaan di Indonesia yang kurang memperhatikan sumber daya manusia (SDM). Ini tercermin antara lain dari minimnya pelatihan dan pengembangan, kurang jelasnya jenjang karier, dan rendahnya pemberdayaan karyawan.

PT. Batavia Bintang Berlian Pulogadung merupakan salah satu perusahaan yang bergerak dibidang pendistribusian barang dan pelayanan jasa. PT. Batavia Bintang Berlian Pulogadung tidak hanya melakukan penjualan negosiasi dalam pembelian mobil.

Ini menjelaskan bahwa kurangnya pelatihan bagaimana mengambil sebuah keputusan yang cepat juga tepat. Karyawan yang diberdayakan memiliki inisiatif dalam bekerja tanpa harus menunggu perintah dari pimpinan. Karyawan yang diberdayakan akan lebih dihormati serta memiliki keberartian dalam pekerjaannya. Hal ini sebagai bentuk penghargaan oleh pimpinan dan akan mempengaruhi kepuasan kerja. Pemberdayaan yang rendah menyebabkan kepuasan kerja juga menjadi rendah. 
Alasan tersebutlah yang melatar adalah kepuasan kerja sebagai variable yang belakangi peneliti untuk melakukan penelitian dipengaruhi.

pada karyawan di PT. Batavia Bintang Berlian Pulogadung secara lebih mendalam.

Diharapkan akan dapat diketahui sampai sejauh mana peran pemberdayaan dapat menimbulkan kepuasan kerja karyawan.

\section{METODOLOGI PENELITIAN}

\section{Tempat dan Waktu Penelitian}

Penelitian ini dilaksanakan di PT. Batavia Bintang Berlian Showroom Mitsubishi yang beralamat di J1. Raya Bekasi Km.19 Pulogadung - Jakarta Timur 13260selama tiga bulan, terhitung dari bulan April 2014 sampai dengan Juni 2014.

\section{Metode Penelitian}

Metode penelitian yang digunakan adalah metode survei dengan pendekatan korelasional dan menggunakan data primer karena data diambil langsung dari karyawan. Melalui pendekatan korelasional akan dilihat seberapa jauh hubungan antara variabel bebas (variabel X) adalah pemberdayaan sebagai variabel yang mempengaruhi dan variabel terikat (variable Y)

\section{Populasi dan Sampling}

Dalam penelitian ini yang menjadi populasi adalah karyawan PT. Batavia Bintang Berlian Showroom Mitsubishi yang berjumlah 120 karyawan. Populasi terjangkaunya adalah karyawan yang berada di divisi marketing yang berjumlah 60 orang. Sampel yang diambil dalam penelitian ini sebanyak 51 responden. Penentuan sampelnya dengan menggunakan tabel Issac \& Michael dengan tingkat kesalahan 5\% sehingga jumlah sampel dalam penelitian ini adalah sebanyak 51 responden. Teknik pengambilan sampel yang digunakan adalah teknik acak proporsional (proportional random sampling.

Tabel III.1

\begin{tabular}{|c|c|c|c|}
\hline $\begin{array}{c}\text { Unit Kerja } \\
\text { Bagian }\end{array}$ & $\begin{array}{c}\text { Jumlah } \\
\text { Karyawan }\end{array}$ & Perhitungan & Sampel \\
\hline Marketing I & 11 & $11 / 60 \times 51$ & 9 \\
\hline Marketing II & 9 & $9 / 60 \times 51$ & 8 \\
\hline Marketing III & 10 & $10 / 60 \times 51$ & 8 \\
\hline Marketing IV & 12 & $12 / 60 \times 51$ & 10 \\
\hline Marketing V & 8 & $8 / 60 \times 51$ & 8 \\
\hline Marketing VI & 10 & $10 / 60 \times 51$ & 8 \\
\hline Total & $\mathbf{6 0}$ & & 51 \\
\hline
\end{tabular}




\section{Teknik Pengumpulan Data}

Penelitian ini melipulti dua variabel, yaitu pemberdayaan (variabel X) dan kepuasan kerja (variabel Y). Instrumen penelitian untuk mengukur kedua variabel tersebut akan dijelaskan sebagai berikut:

\section{Pemberdayaan ( Variabel X )}

\section{Definisi Konseptual}

Pemberdayaan adalah delegasi dan kebebasan yang diberikan pimpinan kepada karyawan untuk melakukan suatu tugas tertentu.

\section{Definisi Operasional}

Pemberdayaan merupakan data primer yang mencerminkan indikator delegasi meliputi wewenang dan tanggung jawab; kebebasan meliputi menemukan ide-ide baru, mengemukakan pendapat, dan membuat keputusan.

\section{Kepuasan Kerja Karyawan (Variabel Y)}

\section{Definisi Konseptual}

Kepuasan kerja adalah suatu perasaan seorang karyawan yang menyenangkan atau tidak menyenangkan terhadap pekerjaannya yang kemudian tampak dalam sikap terhadap organisasi dimana ia berkarya. Dalam hal ini kepuasan kerja tersebut meliputi : pekerjaan itu sendiri, kesempatan promosi, balas jasa, supervisi, dan rekan kerja.

\section{Definisi Operasional}

Kepuasan kerja merupakan data primer yang mencerminkan aspek-aspek dari kepuasan kerja yaitu dimana memiliki dimensi pekerjaan itu sendiri, kesempatan promosi, balas jasa, supervisi, dan rekan kerja.

\section{HASIL DAN PEMBAHASAN}

\section{Teknik Analisis Data}

\section{Mencari Persamaan Regresi}

Analisis regresi linier sederhana terhadap pasangan data penelitian antara pemberdayaan dengan kepuasan kerja menghasilkan koefisien arah regresi sebesar 0.717 dan konstanta sebesar 37.32. Dengan demikian bentuk hubungan antara pemberdayaan dengan kepuasan kerja memiliki persamaan regresi $\hat{Y}=$ $37.32+0,717 \mathrm{X}$. Persamaan regresi ini menunjukkan bahwa setiap peningkatan satu skor pemberdayaan dapat menyebabkan kenaikan kepuasan kerja karyawan sebesar 0,717 pada konstanta 37.32 . 


\section{Uji Normalitas Galat Taksiran Regresi Y}

$\operatorname{atas} X$

Hasil perhitungan Uji Liliefors menyimpulkan

galat taksiran regresi $\mathrm{Y}$ atas $\mathrm{X}$ berdistribusi

normal.

\section{Uji Keberartian Regresi}

Pengujian keberartian regresi untuk menguji apakah persamaan regresi $\mathrm{Y}$ atas $\mathrm{X}$ membentuk garis yang berarti atau tidak (signifikan). Regresi dinyatakan sangat berarti jika berhasil menolak Ho. Jika $F_{\text {hitung }}>F_{\text {tabel }}$, maka Ho ditolak berarti regresi dinyatakan sangat berarti (signifikan).

Dapat dibuktikan dengan hasil perhitungan $F_{\text {hitung }}=37,40$ sedangkan $F_{\text {tabel }}=4,04$ ini berarti $\mathrm{F}_{\text {hitung }}>\mathrm{F}_{\text {tabel, }}$ maka pengujian hipotesis

\section{Uji Koefisien Determinasi}

Uji koefisien determinasi ditujukan untuk mengetahui besarnya variasi variabel $\mathrm{Y}$ (kepuasan kerja) ditentukan oleh variabel $\mathrm{X}$ (pemberdayaan), yaitu $r_{x y}^{2}=(0,658)^{2}=0,4329$ (proses perhitungan pada lampiran 40) sehingga dapat dikatakan bahwa 43,29\% variasi kepuasan kerja ditentukan oleh pemberdayaan.

\section{Perhitungan Koefisien Korelasi}

Selanjutnya, dilakukan pengujian koefisien korelasi. Pengujian ini bertujuan untuk membuktikan apakah terdapat hubungan antara variabel $\mathrm{X}$ dan Variabel $\mathrm{Y}$ dengan menggunakan rumuis koefisien Korelasi Product Moment dari Pearson.

Hasil perhitungan koefisen korelasi antara kepuasan kerja dengan keterlibatan kerja dengan rumus product moment menghasilkan $r_{x y}=0,658$ (Proses perhitungan pada lampiran 38). Ini menunjukkan $r_{x y}>0$, dapat disimpulkan bahwa terdapat hubungan yang positif antara pemberdayaan dengan kepuasan kerja sebesar 43,29\%.

\section{Interpretasi Hasil Penelitian}

Berdasarkan hasil perhitungan yang telah dikemukakan diatas, diketahui adanya hubungan yang positif antara pemberdayaan dengan kepuasan kerja pada karyawan di PT Batavia Bintang Berlian Showroom Mitsubishi di Jakarta Timur.

Dari perhitungan ini pula maka hasil penelitian diinterpretasikan bahwa pemberdayaan mempengaruhi kepuasan kerja. 
Hal ini menunjukkan bahwa pemberdayaan yang tinggi dapat mengakibatkan semakin tingginya kepuasan kerja pada karyawan di PT Batavia Bintang Berlian Showroom Mitsubishi di Jakarta Timur. Sebaliknya pemberdayaan yang rendah akan menyebabkan rendahnya kepuasan kerja pada karyawan di PT Batavia Bintang Berlian Showroom Mitsubishi di Jakarta Timur.

\section{DAFTAR PUSTAKA}

Ardiansyah, Fazmah I, 2009. "Kepuasan Kerja Sebagai Pemediasi Pengaruh Pengaturan Emosi pada Keinginan Untuk Keluar". Jurnal Manajemen \& Kewirausahaan.

Ariawan, 2007. "Pengaruh Motivasi dan Pemberdayaan Terhadap Kinerja Pegawai Badan Keuangan Daerah Provinsi Gorontalo". Jurnal Ichsan Gorontalo. Vol.2, No.3.

Buchanan, David dan Andrzej Husczynski, 2004. Organizational Behavior. London: Pearson.

Cook, Sarah dan Steve Maculay, 2005. Perfect Empowerment. Terjemahan Paloepi Tyas R. Jakarta: PT Elex Media Komputindo.

Daft, Richard L., 2003. Management.USA: Thomson.

Debora, 2006. "Pengaruh Pemberdayaan Kerja dan Psikologis Terhadap Kepercayaan Organisasional dan Kepuasan Kerja Dosen Tetap Perguruan Tinggi Swasta". Jurnal Managemen dan Kewirausahaan, Vol.08, No.2,

Evans, James R., 2005. Total Quality Management, Organizational Strategy.Canada: Thomson.

Ferrel dan Michael D. Hartline, 2008. Marketing Strategy.USA: Thomson.
Griffin, Ricky W, 2004. Manajemen, Jilid 2. Tejemahan Gina Gania. Jakarta: Erlangga.

Handoko, Hani T., 2001. Manajemen Personalia dan Sumber Daya Manusia.Yogyakarta: BPFE.

Henning, Thorsten dan Ursula Hansen, 2000. Relationship Marketing.Jerman: Springer.

Hidayat, 2011. "Analisis Model Pengaruh Dimensi Kepuasan Kerja terhadap Kinerja Karyawan". Jurnal Mitra Ekonomi dan Manajemen Bisnis, Vol.2, No.1.

Husein, Umar, 2005. Riset Sumber Daya Manusia, Edisi Revisi.Jakarta : PT Gramedia Pustaka Utama.

Indrawijaya, Adam Ibrahim, 2004. Perilaku Organisasi. Bandung: Sinar Baru.

Khuzaini dan Thomas S. Kaihatu, 2008. "Pentingnya Kepuasan Kerja dalam Memediasi Hubungan antara Pemberdayaan Anggota terhadap Komitmrn Organisasi”. Majalah Ekonomi, Tahun XVIII, No.3, Desember.

Kreitner, Robert dan Angelo Angelo Kinicki, 2008. Organizational Behavior.New York: McGraw-Hill.

Luthans, Fred, 2008. Organizational Behavior. USA: MC Graw-Hill.

Mangkunegara, Anwar Prabu, 2005. Manajemen Sumber Daya Manusia Perusahaan, Bandung : Remaja Rosdakarya.

Martoyo, Susilo, 2000. Manajemen Sumber Daya Manusia. Yogyakarta: BPFE.

Mullins, Laurie J., 2005. Management and Organizational Behavior.London: Prentice Hall.

Mulyadi dan Johny Setiawan, 2001. Sistem Perencanaan dan Pengendalian Manajemen. (Jakarta: Salemba Empat.

Musanef, 2000. Manajemen Kekaryawanan. Jakarta: Haji Mas Agung.

Nasution, M. Nur. 2005. Manajemen Mutu Terpadu. Bogor: Ghalia Indonesia.

Nongkeng, Hasan, et al., 2012. "Pengaruh Pemberdayaan, Komitmen Organisasional terhadap kinerja dan Kepuasan Kerja Dosen (Persepsi Dosen Dipekerjakan PTS Kopertis Wilayah IX 
Sulawesi di Makasar)". Jurnal Aplikasi Manajemen. Vol. 10, No.3.

Paramarta, Vip, 2004. "Kepuasan Kerja, Teori, Pendekatan, dan Skala Pengukurannya", Jurnal Bisnis, Manajemen dan Ekonomi. Volume 6 No.3.

Riduwan dan Engkos Achmad Kuncoro, 2007. Cara Menggunakan dan Memaknai Analisa Jalur (Path Analysis). Bandung: CV Alfabeta.

Rivai, Veithzal. 2005. Manajemen Sumber Daya Manusia dan Perusahaan dari Teori ke Praktik. Jakarta: Raja Grafindo Persada.

Robbins, Stephen P. dan Timothy A. Judge, 2007. Organizational Behaviour. New Jersey: Prentice Hall.

Siagian, Sondang P., 2001. Manajemen Sumber Daya Manusia. Jakarta: Bumi Aksar.
Sopiah, 2008. Perilaku Organizational. Yogyakarta; Andi OffseT.

Suharsimi Arikunto, ManajemePenelitian. Jakarta: PT. Rineka Cipta, 2009.

Voght, Judith F. dan Kenneth L. Murrel, 2002. Empowerment In Organization. California: University Associates.

Whetten, David A. dan Kim S. Cameroon, 2007. Developing Management Skills. New Jersey: Prentice Hall.

Wibowo, 2007. Manajemen Kinerja. Jakarta : Raja Grafindo Persada.

Williams, Chuck, 2003. Management.USA: Thomson.

Wursanto, I. G., 2000. Dasar-dasar Manajemen Personalia. Jakarta: Pustaka Dian. 